\title{
Study on Graduation Design Teaching Reform Based on Big Data Information for Inter-disciplinary Talent
}

\author{
Zhang Jianwu \\ Tianjin Railway Technical and Vocational College, Tianjin, 300240, China \\ Zjw63@163.com
}

Keywords: Graduation Design; Big Data; Inter-disciplinary Talent; Data Mining

\begin{abstract}
Graduation design plays important role to improve the comprehensive ability of the cultivation object, whose methods and ways influence the training effect directly. This paper takes the computer professional graduation design based on big data information as the research object, and the graduation design topic selection, implementation and evaluation of the entire process as the main process. Using the data mining technology assisted with the internet information resources to avoid the repeatability of the topic selection, the loose of the implementation and the fuzzy of the evaluation for the graduation design, which can obtain good results such as the topic selection with instruction, the implementation has interaction and the evaluation has standard. Meanwhile, the cultivation object can grasp the frontier dynamic and the market demand during the graduation design process, which can improve the theory and practice ability at the same time. As a result, it can help the inter-disciplinary talent growth. Practice has proved that the graduation design using big data information can improve the effect of the cultivation of the inter-disciplinary talent.
\end{abstract}

\section{Introduction}

The new requirements of the cultivation of talents have been proposed recently with the development of science technology and the innovation of the engineering technology. Meanwhile, the new domestic and international engineering standards have been updated and developed. To cultivate the inter-disciplinary talent of the computer professional becomes the most urgent needs. Graduation design plays important role to improve the comprehensive ability of the cultivation object [1], which is a link of practice teaching according to the teaching plan. At present, the graduation design is the periodic basis or professional technical training of the students under the guidance of teachers, and it is a method to cultivate the ability to analyze and solve problems by comprehensive using the theoretical knowledge. However, the graduation design involves topic selection, implementation and evaluation, and the traditional methods and ways of the graduation design shows many shortages in the link above, such as the topic selection is not closely combined with practice, the implementation process lack of interaction and the evaluation has no unified standard [2]. With the development of the internet and the concept of big data is put forward [3], the teaching reform must continue to deepen in the depth and breadth, because more and more information can be provide to teachers and students. This paper takes the computer professional graduation design based on big data information as the research object, and the graduation design topic selection, implementation and evaluation of the entire process as the main process. The graduation design analysis system is established according to big data information, and the topic selection, implementation process and evaluation standard can be instructed by statistics. Using the data mining technology assisted with the internet information resources to avoid the repeatability of the topic selection, the loose of the implementation and the fuzzy of the evaluation for the graduation design, which can obtain good results such as the topic selection with instruction, the implementation has interaction and the evaluation has standard. Meanwhile, the cultivation object can grasp the frontier dynamic and the market demand during the graduation design process, which can improve the theory and practice ability at the same time. As a result, it can help the inter-disciplinary talent growth. The statistics with three years of graduation design result prove that the proposed teaching reform scheme has very good effect. 


\section{The Shortcoming of Traditional Graduation Design}

The computer professional includes computer science and technology professional, computer software professional and electronic commerce professional, etc., which is a wide scope professional combination of hardware and software, oriented system and focusing on the application. The characteristics of the computer professional lead to the difficulty of the graduation design, such as limitation of the selected topics, implementation process is looser and results evaluation are more complex. The traditional graduation design has shortcoming in many aspects, which mainly reflected in the topic selection, implement and evaluation process.

At first, topic selection determines the students what to do of the graduation design, which is the basis of the graduation design. Selected topics source of the traditional graduation design has three problems, which are the selected topics is very limited, the selected topics is far from the practice and the selected topics is not tally with the ability of the student. Most of the selected topics are appointed by the teachers, some selected topics are proposed by the students themselves and a small number selected topics are provided by the cooperative enterprise. The selected topics are often repeat or similar, which lack of effective management mechanism. Furthermore, the selected topics appointed by the teachers are often too dependent on the professional level of the teachers, which are strong theoretical and lack of practical significance. The main body of the graduation design is the student, but there are few students participate in the determination of the selected topics. There is a difference on the abilities and talents of the students, once a student choose a graduation design topic, he must try his best to complete the content and reach to the aim. Some students with good theoretical and practical ability will think the topics are very simple and the harvest is not big, on the contrary, some students will feel particularly difficult and the task cannot be completed. The graduation design topic with the cooperative enterprise is relatively better. However, the above shortcoming still cannot completely overcome.

Secondly, the implementation process of the traditional graduation design is very loose. During the implementation process of the traditional graduation design, there is lack of effective ways and means of cooperation and mutual assistance. The students in different schools cannot share resources about the similar selected topics. The students in different professional cannot establish effective communication. The students instructed by different teachers cannot be convenient to use each other's achievements. Even among the students the progress cannot be full use to provide help each other. This mode of implementation process of graduation design results in waste of resource, and it leads to lots of repetitive work, slow progress and low success. The other problem of the implementation process is lack of effective supervision. The graduation design process control excessive dependence on teachers, once the block communication occur between students and teachers, the whole work will become out of control, and even lead to the key nodes cannot be finished on time. However, the block communication between students and teachers is a common phenomenon for the teachers need to take a number of teaching tasks and the students may have their own private things.

At last, the results evaluation of the traditional graduation design is fuzzy. The results evaluation focuses on the design products and papers, furthermore, the results evaluation generally performed by the review committee which consists of various professional teachers. Although the results evaluation often adopts scoring method according to innovative, reports and product completeness, etc., the evaluation results have very strong subjectivity. As a result, the achievements of the graduation design often tend to be ignored and the unqualified work cannot be pointed out. In the end, the ability of the students in the graduation design is uneven and the teaching goal cannot reach.

Due to the existence of the above problems, the enthusiasm of the students is low and the ability of theoretical innovation and practical improve is not obvious. The students participate in the graduation design cannot meet the expected goal, which includes English reading and translation ability, information literature review, the ability to use with the software tool and unity cooperation ability, etc. The inter-disciplinary talent is necessary for the development of the society in many engineering and research fields. Therefore, the graduation design must adaptability reform. 


\section{The Teaching Reform}

Based on the current situation of computer professional graduation design, our school carried teaching reform on the graduation design topic selection, implementation process and the results evaluation. With the development of internet and information processing technology, big data and cloud computing is changing the people's life [4][5], including the teaching way and method. With the big data information, more resource about graduation design can be obtained and shared, in particular, data analysis and statistics provides help us to dig the regularity, which can be taken as an auxiliary decision-making information to improve the graduation design teaching work [6]. A graduation design management system was design and implement based on big data information, and it has been applied to the graduation design in computer professional of our school. The system can be divided into three parts: topics selected, implement management and results evaluation. The block diagram of the system is shown in Fig.1.

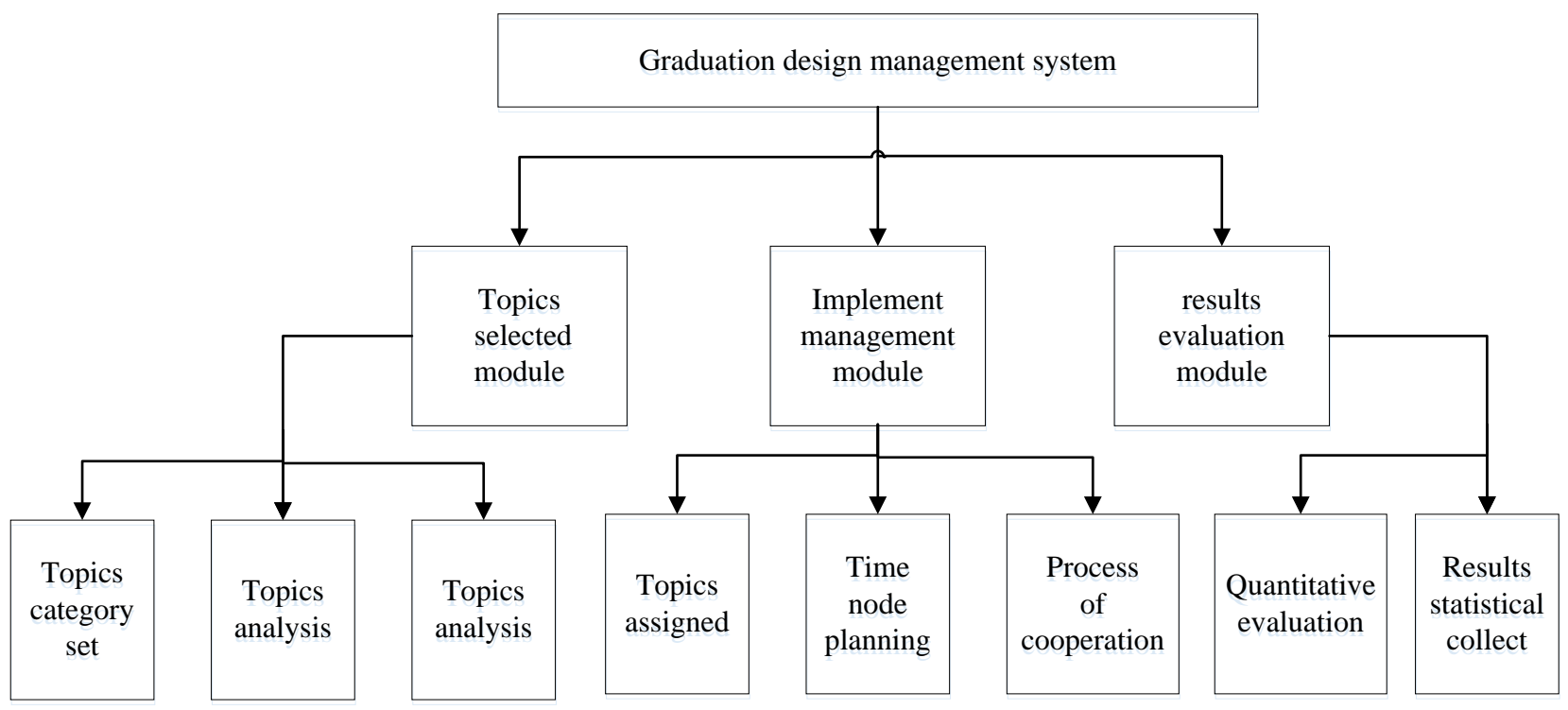

Fig.1 Block diagram of the graduation design management system

\section{A. The Topics Selected Module}

The topics selected module includes topics category set, topics analysis, topics determination and topics assigned. Using the internet for big data statistical analysis to find the research direction which computer major cutting edge and the hotspot engineering application, and the graduation design topics selection is given. The preliminary graduation design topics are given according to the topics category, and the topics analysis can implement further refined processing. The graduation design topics have been completed by our past students or other colleges and universities will be removed from the preliminary graduation design topics, of course, the information of the topics can be come from the database of our school and the internet combined with other colleges and universities. This function of the system can avoid many topics of repetitive or too old, which can ensure the selected topics meet the demand of the cultivation of inter-disciplinary talent. Furthermore, the module implements the theory and practice evaluation on the selected topics, which can also come from the teacher assigned, students themselves or the cooperative enterprise. The quantitative evaluation of the selected topics for theory and application can be done according to the study content, and also the difficulty coefficient and the required time must be taken into account. For the selected topics are excessive theory or excessive practice for the cultivation of inter-disciplinary talent is appropriate, it must be removed or modified for the unreasonable topics until all the selected topics meet the unity of theory and practice.

\section{B. The Implement Management Module}

The implement management module includes topics assigned, time node planning and process of cooperation. Topics assigned involve the professional branch, the assessment of the students and the determination of the guide teachers, and all the factors must seriously consider forming a good 
configuration. Computer professional branch is broader and the difference of professional courses of the students is bigger. The students must register their own professional courses in the system, and the register information can be further checked and corrected according to the database of the office of teaching by the network connection. The function can avoid too big gap between the topics chosen by students and their major. The topics assigned must be carried out according to different students' ability. Although each graduation design selected topics should keep consistent on difficulty in teaching plan, in order to achieve talents distinguish between levels training and ensure that students can gain maximum profits in graduation design work, the graduation design selected topics should be to distinguish, that is the selected topics should maintain proportion relationship among hard, moderate and easy topics. The difficulty of the topics assigned should be matching with the students' ability. Otherwise, the teaching goal of graduation design cannot be reached. The students can register their scores of courses in the system, and the scores also are checked and corrected according to the database of the office of teaching. Meanwhile, the selected topics are sorted in accordance with the difficulty, and then students can choose their graduation design topics according to their professional and the difficulty of the selected topics. This function can avoid the large gap between the selected topics and the students' ability in traditional graduation design work, as a result, it can avoid the students with strong ability improve is limited and the students with weak foundation meet many difficulties in the process.

Time node planning control is another important function of the implement management module. The time node planning is commonly designed together by teacher and student after communication and discussion, and the key time node must be pointed out in the plan. Students should complete the progress or achievements report and upload them to the system, where the progress and achievements are shared and visible to all students and teachers. Individual student may meet problems on time node and fail to finish the task specified in the plan. Once these problems happen, the time node planning must be adjusted in time and the reason must be master, and the reason should be summarized to the system as the source information to improve the system function.

Cooperation is one of the basic qualities of the interdisciplinary talent. In the traditional graduation design process, there has gap between the different schools, the different professional and among the students, which hinder the progress of the whole process and affects the realization of the goal. The function of the process of cooperation can gather and share the graduation design achievements timely, and provide reference source through internet. The students can find the resource similar to themselves in the system and online communication and off-line cooperation become convenient. This function implements resources sharing and improve the cooperation ability of the students'.

\section{The Results Evaluation Module}

The results evaluation module implements quantitative evaluation of the graduation design work and results statistical collect. The traditional graduation design evaluation relies heavily on grading teachers and it has large subjective. Meanwhile, the management of the graduation design results of the graduation has no effective means and standardize, which cause many meaningful results have no extending application. In this system, the results evaluation of the graduation design adopts quantitative method through the whole process that is the score of a graduation design work is summarized by the selected topics according to the difficulty and time consumption, the achievements of the time nodes in the plan, the cooperation process and the final product output. In this way, the teachers' evaluation is only as part of the whole evaluation. Based on the evaluation results, the special skills and lack of space can be pointed out for the students.

Results management for graduation design work cannot be ignored. The results evaluation module takes the achievements of graduation design management as a project alone, which makes classification, analysis and statistics of graduation design results. The graduation design results can be classified according to the professional and the user can query conveniently. The subsequent students can put these results for own graduation reference. Furthermore, some excellent results can be further study and convert to the application project. 


\section{Conclusion}

This work proposed a method that the computer professional graduation design based on big data information, based on which the graduation design management system is design and implement. Using this system for the three years of computer professional graduates in our school has carried on the practice, involving a total of 1802 students. Practice proved that using this system to guide the graduation design work effectively to improve the effect of the inter-disciplinary talent, the completion rate increase by $12 \%$ and the achievements conversion rate increase by $26 \%$.

\section{References}

[1]WANG X. L., SONG Y. Study on the training of students' innovation ability in course design [J]. China Modern Educational Equipment, 2010, (3): 137-139.

[2]NING X. S. Characteristics and training ways of high quality engineering and technical personnel [J]. Science and Management, 2006, (4): 17-19.

[3]FRANK Canters and WILLIAM De Genst. Assessing of input uncertainty in structural landscape classification [J]. INT. J. Geographical Information Science, 2002, 16(2): 129-149.

[4]Xiaozhong Chen and Natalia A. Trayanova. A novel methodology for assessing the bounded-input bound-output instability in QT interval dynamics: application to clinical ECG with ventricular tachycardia [J]. IEEE Tras Biomed Eng, 2012, 59(8): 2111-2117.

[5]L.F.M. Sanchez, B. Fournier, M.Jolin, J.Bastien. Evaluation of the stiffness damage test (SDT) as a tool for assessing damage in concrete due to alkali-silica reaction (ASR): input parameters and variability of the test response [J]. Construction and Building Materials, 2015, (77): 20-32.

[6]Zeng Tao. The design and implementation of the control center of the smart-home based on android system [D]. School of Computer \& Engineering, 2011. 